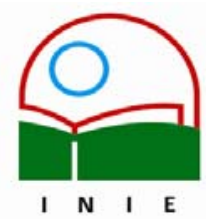

Universidad de Costa Rica

Facultad de Educación

Instituto de Investigación en Educación

ACTUALIDADES INVESTIGATIVAS EN EDUCACION

\title{
LA ENSEÑANZA DE LAS ARTES PLÁSTICAS EN LA UNIVERSIDAD DE COSTA RICA
}

\author{
Julieta Castro Bonilla ${ }^{1}$
}

"En un sistema educacional bien equilibrado, en el cual se acentúe la importancia del desarrollo integral; la capacidad intelectual, los sentimientos y las facultades perceptivas de cada individuo, deben ser igualmente desarrolladas, con el fin de que su capacidad creadora potencial pueda perfeccionarse". Lowenfeld Víctor.

Resumen: El presente artículo gira en torno de una revisión bibliográfica, mediante la cual se reflexiona respecto a los antecedentes, trayectoria e importancia que posee la enseñanza de las Artes Plásticas en la educación en nuestro país. Se hace referencia a la responsabilidad que tiene la Universidad de Costa Rica como una institución académica que se funda en el año 1940, y adquiere el compromiso con la sociedad de brindar profesiones con cualidades humanas, culturales y sociales. Se considera que ha ido a la vanguardia en cuanto a la formación de docentes en esta área creativa. Finalmente se realiza un comentario del plan de estudios vigente, el cual responde a las necesidades de la población estudiantil y de la sociedad costarricense.

Palabras claves: ENSEÑANZA DE LAS ARTES PLÁSTICAS/ EVOLUCIÓN Y TRAYECTORIAI UNIVERSIDAD DE COSTA RICA-INSTITUCIÓN FORMADORA DE DOCENTES/ PLAN DE ESTUDIOS VIGENTE/

Abstract: In the following article, a bibliographic revision is done with the purpose of pondering the background, the course of development and the importance of the teaching of the Fine Arts in education. It refers to the Universidad de Costa Rica's responsibility as an academic institution at the forefront regarding the training of teachers in this creative field, and finally the current study plan, which answers the necessities of the student population and those of the Costarican society.

Keywords: TEACHING/ COURSE OF DEVELOPMENT AND EVOLUTION OF THE FINE ARTS/ UNIVERSIDAD DE COSTA RICA AS A TEACHER TRAINING INSTITUTION/ CURRENT STUDY PLAN/

\section{Introducción}

El valor que posee la enseñanza de las Artes Plásticas en la formación del niño y del joven es invaluable, debido a su acción estimuladora de la creatividad y a su función integradora de las áreas emocional, física e intelectual. Dentro de las Artes Plásticas, la

\footnotetext{
${ }^{1}$ Magíster en Ciencias de la Educación con énfasis en Educación Artística. Licenciada en Bellas Artes con especialidad en Pintura. Profesora de Educación Secundaria con énfasis en Artes Plásticas. Actualmente es profesora de la Escuela de Formación Docente e Investigadora del Instituto de Investigación en Educación (INIE) de la Universidad de Costa Rica.
}

Correo electrónico: inie@cariari.ucr.ac.cr

Artículo recibido: 25 de octubre, 2004

Aprobado: 13 de diciembre, 2004 
escultura, la pintura, el modelado, el grabado, y la apreciación artística, entre otras, favorecen el desarrollo de una personalidad integral, dado que se consideran una ventana mediante la cual los estudiantes pueden mostrar su interioridad, de la misma manera que apreciar el mundo exterior, lo que les permite un enriquecimiento intelectual y emocional que fortalecen su autoestima.

En el proceso artístico, cada experiencia le aporta al estudiante nuevos datos, que al acumularlos, van modificando y enriqueciendo sus esquemas expresivos, por lo tanto, a medida que crecen, varía también su comunicación creativa.

De acuerdo con la bibliografía estudiada y tomando en cuenta mi experiencia como profesora de Artes Plásticas, se considera que el Ministerio de Educación Pública ha hecho grandes esfuerzos por impulsar políticas tendientes al mejoramiento de la educación entre las que se destacan los novedosos planteamientos en 1990, al establecer las bases del constructivismo como un enfoque curricular que sirviera de soporte a los procesos de enseñanza y aprendizaje, y de esta manera, se logra revitalizar la práctica docente de los educadores, mediante metodologías innovadoras, que permitan el logro de aprendizajes significativos de parte de los estudiantes. Con la aplicación del constructivismo se pretende el mejoramiento integral del proceso educativo, por lo que los docentes se vieron impulsados a transformar sus formas tradicionales de trabajo, por otras más novedosas con el propósito de enriquecer su labor docente. Es importante indicar que en el desarrollo de la capacidad creadora del estudiante, influyen de manera directa aspectos como; el ambiente social, familiar y el socioeconómico en que se desenvuelve, así como los factores culturales propios de la época, su relación e interacción con amigos y compañeros, sus experiencias dentro y fuera del contexto de aula, incluyendo su propia personalidad, además, no existe la cultura en nuestra población para visitar museos, galerías de arte, asistir al cine o al teatro o participar en actos culturales, por lo que le corresponde al docente de expresión artística organizar programas de estudios conducentes al desarrollo de la capacidad creadora de su población estudiantil.

A pesar de que el estudio se refiere a la enseñanza de las Artes Plásticas en la educación secundaria, deseo indicar que esta área es considerada fundamental durante la educación preescolar y primaria. Los autores Lowenfeld V. y Read H., conciben la infancia como un momento de gran potencial creativo, y la educación en disciplinas artísticas debía explorar ese potencial interior en beneficio del desarrollo personal del niño. Por lo tanto, se considera prioritario ofrecerle, desde pequeño, experiencias que impliquen descubrimientos con colores, texturas y actividades de arte en dos y tres dimensiones, que favorezcan la 
ampliación de sus marcos de referencia, para lo que es importante la estimulación de los sentidos, ya que además de enriquecer sus imágenes, desarrollará su propia sensibilidad estética y su juicio crítico, favoreciendo de esta manera, la construcción de su autonomía. Este tipo de experiencias artísticas se deben ofrecer, desde la educación preescolar, para que cuando el estudiante ingrese a la educación primaria, el proceso artístico no se detenga y pueda continuar construyendo imágenes que le permitan fortalecer sus propias capacidades de producción, así como comunicar a otras personas los contenidos y significados de su interacción con el mundo. Según Spravkin M. (1997), niño se sirve del dibujo, de la pintura, del modelado y de la construcción para expresar y comunicar, es decir para clarificarse a sí mismo y a los demás los contenidos de su pensamiento y de su fantasía.

La vivencia de experiencias artísticas desde la educación preescolar como se han descrito, le permiten el estudiante hacer su ingreso a la educación secundaria con un elevado desarrollo creativo, lo que le facilita interpretar la realidad desde diversas formas expresivas, así como adentrarse y apreciar las diferentes expresiones de arte que ofrece la cultura. De acuerdo con lo expuesto, le corresponde a las instituciones escolares y, específicamente al docente, ofrecer a las personas desde pequeñas, oportunidades de expresión y de creación, así como la facilidad de ponerse en contacto con artistas y con obras de arte, con el propósito de iniciar el camino hacia la apreciación de la cultura desde muy jóvenes.

\section{La importancia de las Artes Plásticas para la formación integral del estudiante}

La enseñanza de las Artes Plásticas es considerada una actividad dinámica que desempeña una función vital en la educación. El dibujo, la pintura, la escultura, la construcción y otras formas expresivas, se concretan mediante procesos de creación cuando una persona es capaz de reunir elementos de su imaginación, de su mundo exterior, de sus experiencias y aprendizajes, para formar un producto concreto, que lo identifica como un ser único. En este proceso de interpretación y de creación, el estudiante proporciona parte de sí mismo; nos revela cómo piensa, cómo se siente, cómo resuelve los problemas y cómo los concreta, Lowendeld V. (1984).

Se entiende que la expresión artística representa, en una persona, la exteriorización visual de su pensamiento, de sus emociones y sentimientos, de sus conocimientos y de su mundo. De acuerdo con lo expuesto, las artes plásticas contribuyen a la formación de una 
personalidad integral en el estudiante, por lo que se considera una tarea prioritaria de parte del docente, la organización de actividades lúdicas, así como brindarle los recursos necesarios para que el joven pueda utilizar el arte como un medio de expresión que le brinda confianza y le permita proyectarse y fortalecer sus desarrollos: afectivo, psicomotor y cognitivo. Desafortunadamente en muchas de nuestras instituciones públicas, el profesor de artes no cuenta con un espacio cómodo para desarrollar las actividades que él mismo programa.

Se sabe que nuestro sistema educativo asigna gran importancia al aprendizaje cognitivo, a pesar de esto, el Ministerio de Educación Pública siempre ha considerado como parte del currículum escolar obligatorio en las instituciones públicas, áreas que dan énfasis al desarrollo afectivo y psicomotor. Me refiero a la enseñanza de las artes plásticas, música, educación física y artes industriales, que le permiten al estudiante la capacidad de descubrir nuevas y diversas formas de expresión, de pensar y de hallar respuestas diferentes, así como de cometer errores y encontrar soluciones. En este sentido, lo importante es ofrecerle al joven la oportunidad de desarrollar su sensibilidad y su capacidad de reflexionar y de producir en cualquiera de las áreas curriculares mencionadas.

De acuerdo con Norma de Panero y otros $(2001,58)$, los elementos del código del lenguaje plástico indican con precisión cómo se conforma su estructura. Para manifestarse, el lenguaje plástico requiere de elementos artísticos como: puntos, líneas, formas, figuras, colores, valores, texturas, proporciones y experiencias espaciales, de la misma forma que de contenidos conceptuales que son los que se concretan plásticamente a través de procedimientos o técnicas de expresión como: dibujos, pinturas, collage, técnicas mixtas, grabados, construcciones o modelados. Según la misma autora, en la estructura del lenguaje plástico, las Artes Plásticas favorecen el desarrollo afectivo mediante la expresión de sentimientos como: la amistad, el amor, la tristeza y otros, a través de la exploración con diversas posibilidades gráficas y en función de lo que necesite expresar. En lo cognitivo, al ser el dibujo o cualquier otra expresión gráfica, la exteriorización del pensamiento, de lo que se sabe, de lo que pudo percibir e interpretar, esta construcción es considerada una actividad mental donde el desarrollo intelectual se encuadra dentro de etapas evolutivas, de acuerdo con la edad de quien ejecute la acción. Respecto al área psicomotora, las artes le permiten al joven el fortalecimiento de habilidades y destrezas mediante la manipulación de diversos materiales (carboncillo, témperas, arcilla, y otras) y técnicas artísticas (dibujo, pintura, modelado, etcétera). De acuerdo con lo expuesto, la enseñanza de áreas expresivas debe estar a cargo de docentes con una formación de calidad, tanto en el campo artístico 
como pedagógico; deben tener además una auténtica fe en sus estudiantes y estar dispuestos a aceptar, no solo su propia forma de ser, sino la de sus estudiantes, ya que le corresponde organizar ambientes escolares que promuevan la capacidad creadora y la oportunidad de transformar esos conocimientos, inquietudes reales o imaginados, deseos y emociones de sus estudiantes en formas artísticas concretas. Por consiguiente, considero que no hay razón alguna para que no se pueda organizar un programa de arte con un alto grado de efectividad, que proporcione las bases necesarias para ayudar a satisfacer las necesidades de sus estudiantes, lo que posibilita su desarrollo de una personalidad integral.

Para concluir este apartado, reitero que los programas de arte en instituciones de educación preescolar, primaria y secundaria, deben ser activos y significativos para los estudiantes, por lo que el docente, además de considerar los temas y actividades sugeridas mediante los planteamientos curriculares del Ministerio de Educación Pública, puede tomar en cuenta otros que puedan ser concretados de manera creativa y a través de la expresión artística, entre los que se pueden citar el medio ambiente, la educación sexual, los valores, la educación cívica, y otros temas de interés sugeridos por los mismos estudiantes.

\section{La enseñanza de las Artes Plásticas, antecedentes}

Desde los orígenes de nuestra historia, los jefes de Estado han impulsado la educación. No hay Presidente de la República que no haya dejado impreso su nombre en la historia por su participación en los procesos educativos. Nuestro primer jefe de Estado, Juan Rafael Mora Fernández fue un maestro y su esfuerzo por levantar la educación y la cultura, fue continuo y sobresaliente.

La importancia que se le ha dado a la educación, en cuanto a la formación y consolidación de los valores en los ciudadanos, es notoria y se evidencia una constante preocupación por la educación de la juventud; es así como desde 1812, cuando se crean los ayuntamientos; se estimula el interés por la instrucción; se abren escuelas en villas y pueblos, contratando maestros a pesar de los limitados recursos económicos con los que contaba el Estado para invertir en la educación.

En 1957 se encontraba vigente la "Ley de Educación Común de 1886", incorporada al código de Educación de 1944. Consistía en una compilación de reglamentos, leyes y disposiciones, que con el devenir del tiempo, se hicieron obsoletos. La Costa Rica de 1886, requería de una educación con fines, metas y objetivos concretos, que guiaran la labor del educador. Durante este período, el Consejo Superior de Educación se dio a la tarea de 
elaborar el Proyecto de Ley Fundamental de Educación, el cual fue promulgado por la Asamblea Legislativa, el 25 de septiembre de 1957.

En el artículo segundo de esa ley se indican los siguientes fines de la educación costarricense:

- La formación de ciudadanos amantes de su Patria, conscientes de sus deberes y sus derechos y de sus libertades fundamentales, con profundo sentido de responsabilidad y de respeto a la dignidad humana

- Contribuir al desenvolvimiento pleno de la personalidad humana.

- Formar ciudadanos en una democracia en la que se conciben los intereses del individuo con los de la comunidad.

- Estimular el desarrollo de la solidaridad y la comprensión humana

- Conservar y ampliar la herencia cultural, impartiendo conocimientos sobre la historia del hombre, las grandes obras de literatura y los conceptos filosóficos fundamentales

Estos fines, que presentan una orientación filosófica, muestran el ideal de hombre que la sociedad costarricense quiere formar. Son considerados el punto de partida para establecer las propuestas programáticas curriculares que emite el Ministerio de Educación Pública, así como los objetivos de los diferentes ciclos de enseñanza que conforman nuestro sistema educativo. Las concepciones filosóficas expuestas permiten planteamientos curriculares que inciden directamente en los programas que se constituyen en el punto de partida para el trabajo de aula de los docentes. De esta manera, se originan los programas de estudio para cada una de las áreas que conforman el currículum escolar, entre los que se encuentra el que corresponde a las artes plásticas. Por lo tanto, surgen los objetivos generales y específicos de cada uno de los ciclos educativos: Primero y Segundo Ciclos de la Educación General Básica y Educación Diversificada, que a su vez, permiten la estructuración de los objetivos generales y específicos, contenidos, actividades y evaluación, elementos de la planificación curricular que el profesor debe adecuar al contexto de aula, a los intereses, a las condiciones socio-económicas y a la edad de los estudiantes, pues orientan su trabajo cotidiano. 


\section{La Universidad de Costa Rica, institución formadora de docentes}

En el presente apartado se hace referencia a la importante labor, que en materia de educación y específicamente en el área de la enseñanza de la Artes Plásticas, ha tenido la Universidad de Costa Rica, como institución docente que contribuye con la sociedad costarricense brindándole los profesionales que requiere.

- Desde 1940, la Universidad de Costa Rica, por medio de las Facultades de Ciencias y Letras y Educación, ofrece en forma conjunta planes de estudio para la formación de profesores. Con el tiempo, éstos se transforman y se incorporan novedosos planteamientos curriculares con el propósito de ofrecer día con día, un profesional de la docencia con una sólida formación universitaria, que le garantice éxito en sus funciones como educador, ya que éste es considerado un agente transformador de la sociedad. De acuerdo con la literatura estudiada, es importante indicar que en 1946, aparece el primer plan de estudios, conformado por dos importantes actividades académicas: un curso preparatorio para maestros y profesores de dibujo, y un curso de especialización en pintura, escultura y grabado, con una duración de tres años.

- En 1950, se cuenta con un nuevo plan de estudios que contempla dos aspectos:

- Un curso preparatorio para maestros y profesores de dibujo, con 3 años de estudio.

- Cursos de especialización en pintura, escultura y grabado.

Lo expuesto evidencia una preocupación constante de la Escuela de Bellas Artes de esta Universidad por brindarle al país docentes calificados en el área de las Artes Plásticas, ofreciendo cursos especializados para maestros y profesores de dibujo. Para ingresar a esta academia, era requisito la aprobación y presentación del Certificado de Conclusión de Estudios Secundarios; al aprobar el tercer año universitario, debía presentar una certificación de haber cumplido durante el último año de estudios un total de 15 horas lectivas de práctica docente en instituciones de enseñanza primaria reconocidas por el Estado. El interesado debía solicitar a la Dirección de la Escuela, las pruebas correspondientes para optar por el certificado que lo acreditaría como "Maestro de dibujo en las escuelas primarias". Esas pruebas 
versarían sobre: dibujo, un test general sobre asignaturas académicas, así como una conferencia pública.

- En 1887 y bajo la Dirección del pintor don Tomás Povedano, se funda en el país la Academia de Bellas Artes, la que pasa a formar parte de la Universidad de Costa Rica en 1940. Entre sus finalidades se citan las siguientes:

- Promover la cultura artística en el país en lo que se refiere a las Artes Plásticas.

- Estimular por todos los medios a su alcance la producción artística.

- Preparar a los maestros y profesores de las Artes Plásticas que el Ministerio de Educación necesita dentro del plan educacional del país.

Cabe destacar que desde su fundación, sus directores consideraron conveniente la formación de docentes en Artes Plásticas: lo anterior se ratifica en el siguiente lema: La enseñanza y la difusión de las Artes estimulan y desarrollan las facultades artísticas de los alumnos, a fin de crear interés por todas las manifestaciones estilísticas y enseñar la sensibilidad al país en general; de esta manera, se inicia la preparación de profesores para la enseñanza del arte en la Universidad de Costa Rica, la que refleja una visión prospectiva y optimista.

Reglamento General de la Escuela de Bellas Artes. (1949).

Entre los objetivos que tuvieron las Facultades de Ciencias y Letras, Educación, y la Escuela de Bellas Artes, fue la preparación de profesores para la enseñanza del arte. Con este propósito se ofrecieron cursos para:

- Profesorado en Bellas Artes

- Licenciatura en Bellas Artes

En el capítulo I del mismo Reglamento se menciona:

La Escuela de Bellas Artes es una institución de enseñanza universitaria, que tiende a impulsar y desarrollar las facultades artísticas y estéticas del alumnado, fomentando la afición a toda manifestación artística, tan necesarias en el desarrollo cultural del país y difundiendo esta cultura con todos los medios a su alcance. Al mismo tiempo, busca preparar buenos maestros de dibujo, que tanta falta hacen en las escuelas secundarias de la Nación. 
El Artículo III cita: "La enseñanza que se imparte es teórica y práctica, y abarca el dibujo, la pintura, el modelado, la perspectiva, la escultura, la anatomía, el dibujo anatómico, el dibujo comercial, la xilografía, la escenografía y la pedagogía, la metodología y filosofía del arte, etc.". Cabe destacar que en las citas mencionadas, se destaca el pensamiento prospectivo de quienes elaboraron el currículo mencionado, pues conocían muy bien la responsabilidad que tenía el docente de Artes Plásticas en las instituciones educativas del país, y de esta forma, incluyen dentro del plan del estudios, cursos correspondientes al área pedagógica y metodológica, lo que permitía brindarle al futuro educador una formación sólida.

Cabe destacar que en la actualidad, las Escuelas de Estudios Generales, Artes Plásticas y la de Formación Docente de la Universidad de Costa Rica, participan de manera conjunta y en total armonía, brindando a los futuros docentes una formación humanística, artística y pedagógica de calidad, la que les permite incorporarse en instituciones de primero y segundo ciclos con una visión amplia de sus tareas, deberes y responsabilidades como participantes en la formación de nuestra niñez y juventud costarricenses.

\section{La enseñanza de las Artes Plásticas, su evolución a través de la historia}

Entre los documentos estudiados, se rescata que las artes plásticas siempre han tenido presencia en los programas de enseñanza. A continuación se mencionan algunos de éstos:

- En el documento denominado "Boletín de Las Escuelas Primarias, N 92 ", que data de 1902, aparecen artículos importantes de mencionar: Modo de despertar el interés de los niños por la pintura; Sobre la enseñanza del dibujo en la escuela; Experimentos psicológicos: dibujos de los niños, El dibujo nuevamente en las escuelas. En otro de los artículos se destaca “...la importancia de la asignatura del dibujo, que todo país culto debe tener en cuenta, tanto por sus condiciones educativas como por su utilidad práctica. En otro apartado se indica "...es de rigor que se enseñe el arte en las escuelas del Estado a la par de otras asignaturas obligatorias, ello en efecto se ha venido enseñando sin interrupción desde hace algún tiempo". 
- Entre los textos consultados, aparece en 1950 un plan de estudios para docentes que desean laborar en la educación secundaria; se trata de la "Enseñanza del dibujo para los tres primeros años de estudio y se debían impartir dos lecciones semanales".

- Otro de los documentos indica que en 1951, fue la primera vez en la historia de la Segunda Enseñanza costarricense que son llamados los profesores a realizar un trabajo de carácter técnico-pedagógico. Su objetivo fue "Fijar los propósitos específicos que debía alcanzar la enseñanza de cada materia en particular, o de cada grupo de materias afines, definidos en términos de conocimiento, habilidades $y$ actividades". Los profesores se agruparon por departamentos, entre ellos el correspondiente a las artes e incluía a los profesores de dibujo y música. Se pretendieron unificar criterios para cada una de las áreas afines, en este caso: dibujo, pintura, música, cerámica, declamación, arte dramático, danza, aprendizaje de instrumentos y coro. La educación artística no solo poseía un carácter estético, sino también vocacional.

- El mismo documento informa que la Comisión que sugiere la Reforma de la Segunda Enseñanza, propone el siguiente contenido para el área artística: dibujo, composición, diseño, ilustraciones, pintura y apreciación del arte. Antes de esta fecha, lo único que se menciona en cuanto al contenido del programa, es la investigación de áreas comunes: música, dibujo, decoración, modelado, bajo la denominación de Educación Artística.

- En febrero de 1958, la Misión de Asistencia Técnica de la UNESCO, realizó el segundo "Curso de Perfeccionamiento", para la Enseñanza Media. En éste se analizaron los objetivos de las diferentes asignaturas, incluyendo la selección de contenidos, las actividades, los métodos y la evaluación. Se observaron lecciones en instituciones con guías previamente organizadas. Se hicieron críticas y auto-críticas de esas lecciones, cabe mencionar que la enseñanza de las artes plásticas también fue objeto de estudio.

- En el libro Artes Plásticas 1, Villegas W. (1970, p. 3) escribe: el nombre de la asignatura Artes Plásticas apareció por primera vez llevado a la práctica en nuestro sistema educativo, a partir de 1964, y como parte de un plan de estudios en la 
educación secundaria en el año 1957. Cuando se puso en práctica la reforma de la Enseñanza Media, vino a actualizar el clásico y tradicional dibujo que se impartía desde la formación de los primeros centros educativos del país.

- A partir de 1968, el Consejo Superior de Educación la reconoció como asignatura, que en igualdad de condiciones, forma parte de los planteamientos curriculares emanados por el Ministerio de Educación Pública. Gracias a las políticas del mismo Ministerio, así como al esfuerzo de sus mismas autoridades, en la actualidad las artes plásticas se imparten en gran parte de las instituciones de la Enseñanza General Básica: I y II ciclos; así como en todas las instituciones académicas diurnas del III ciclo (dos lecciones semanales) y en la Educación Diversificada (una lección semanal).

De acuerdo con la documentación estudiada, es importante resaltar que la enseñanza de las Artes Plásticas ha estado siempre presente en el contexto educativo costarricense, lo que le ha permitido a muchos de nuestros niños y jóvenes, incursionar en actividades de apreciación estética que facilitan su desarrollo de las áreas: socio-afectiva, psicomotora y cognitiva, y a su vez, permiten el disfrute de las manifestaciones de arte que ofrece nuestra cultura, y de esta manera, se logra participar en el rescate de nuestras raíces culturales.

\section{Los procesos de capacitación}

En 1968, Costa Rica vivía un momento de crisis, en cuanto a la formación académica de docentes para laborar en la enseñanza media; una de las soluciones al problema fue la de preparar al maestro normalista (con formación en educación primaria), a fin de profesionalizarlo de la forma más conveniente para el ejercicio docente, en el nivel de educación secundaria.

Al respecto el señor Gutiérrez J. (1969), indica, “...la formación acelerada de profesores, partiendo del maestro como profesional docente, propende robustecer la técnica de la enseñanza, sistematizar las condiciones de aprendizaje y a dar solidez a los contenidos programáticos que al profesor le son confiados..." por lo que el Ministerio de Educación Pública asume la responsabilidad de capacitar a maestros de educación primaria, interesados en laborar en la enseñanza secundaria. 
A pesar de que el artículo se refiere a la formación de profesores de Artes Plásticas en la Universidad de Costa Rica, considero importante mencionar que en 1968, la Escuela Normal Superior (actual Universidad Nacional), a través de División de Capacitación, inició un programa cuya meta fue el otorgamiento de títulos profesionales para el ejercicio docente de la Enseñanza Media a aquellos profesores en servicio y aspirantes. Para ello inició sus tareas el lunes 8 de ese año, al asumir el compromiso de ofrecer entre otras áreas de estudio, la enseñanza de las Artes Plásticas.

Los programas fueron elaborados por un Consejo Directivo y por los Asesores de Enseñanza Media del Ministerio de Educación Pública, quienes a su vez, estuvieron bajo la supervisión de todo el proceso organizativo de las diferentes áreas de estudio, incluyendo la selección de los contenidos por desarrollar.

El plan de capacitación en el área de las Artes Plásticas tuvo los siguientes énfasis o áreas de estudio:

- Historia del Arte

- Estética

- Actividades de taller

Estas tres áreas de formación académica y artística fueron objeto de estudio de parte de los docentes participantes. Las actividades culminaron con la puesta en práctica de los conocimientos adquiridos en instituciones de educación secundaria. Las experiencias fueron supervisadas por el asesor de Artes Plásticas del Ministerio de Educación Pública. En éstas se valoraron los conocimientos adquiridos en el área de la Apreciación Artística, mediante la planificación de lecciones. (Ministerio de Educación Pública-Escuela Normal Superior, Departamento de Artes Plásticas, Programas para el Curso de Verano de agosto de 1969).

La Universidad de Costa Rica también ha respondido de manera decidida y oportuna ante las demandas de la sociedad, por lo que ha participado en los siguientes programas y actividades de capacitación a docentes en esta área artística.

Durante 1975 y 1978, las Escuelas de Formación Docente y Artes Plásticas, unen sus esfuerzos y participan en la capacitación de docentes que se encontraban laborando en instituciones del primero y segundo ciclos de la Enseñanza General Básica, sin poseer una preparación adecuada. Esta consistió en brindarles una preparación básica en las áreas: artística y pedagógica, con el propósito de que se desempeñaran de la mejor manera en los procesos de enseñanza y aprendizaje. 
En 1979, la Facultad de Educación (mediante la Escuela de Formación Docente) y la Facultad de Bellas Artes (a través de la Escuela de Artes Plásticas), desarrollan programas tendientes a capacitar personal en servicio no titulado, con el propósito de elevarlo a un nivel mínimo aceptable para el ejercicio de la docencia. Mediante gestiones realizadas por la subcomisión de Profesores de Segunda Enseñanza (A.P.S.E.), se conforma una comisión para que elabore un curso de capacitación dirigido a profesores de Artes Plásticas para el Tercer Ciclo de la Enseñanza General Básica y Educación Diversificada. En este plan participaron profesores nombrados por el Ministerio de Educación Pública, sin tener una formación idónea, pues debido a la escasez de docentes en esta área, se tuvo que acudir a este tipo de nombramientos especialmente en instituciones de zonas rurales del país. El programa de estudio fue elaborado de manera conjunta entre las Escuelas de Artes Plásticas y Formación Docente y se otorgarían los siguientes certificados:

- Certificado de Aptitud Superior, si el estudiante poseía el título de maestro normalista (Profesor de Enseñanza Primaria), con base en el Bachillerato de Segunda Enseñanza.

- Certificado de Aptitud, se otorgaba si el estudiante poseía el diploma de Bachillerato de Segunda Enseñanza. Este certificado le permitía obtener la categoría VT-2 de la Ley de Carrera Docente.

Es importante indicar que se efectuaron las siguientes promociones:

\begin{tabular}{|c|c|c|c|}
\hline Promoción & Año & $N^{\circ}$ de alumnos & Sede \\
\hline $\mathbf{N}^{\circ} \mathbf{1}$ & $\mathbf{1 9 7 9 - 1 9 8 0}$ & $\mathbf{2 0}$ & Rodrigo Facio \\
\hline $\mathbf{N}^{\circ} \mathbf{2}$ & $\mathbf{1 9 8 1 - 1 9 8 2}$ & $\mathbf{2 0}$ & Rodrigo Facio \\
\hline
\end{tabular}

El plan de estudios tuvo una connotación especial, ya que no incluía cursos del área de Cultura General, correspondiente a los Estudios Generales, debido a que los participantes no realizaron las "pruebas de aptitud académica" y "de habilidad", requisitos indispensables para ingresar a la Universidad de Costa Rica y a la Escuela de Artes Plásticas. El planteamiento curricular tuvo un total de 52 créditos, de los cuales 24 correspondieron a la formación artística (12.48\%), y 26 créditos al área de educación (13.52). Los estudiantes que 
concluyeron el total de los cursos programados, consideraron que la formación recibida fue idónea, pues les permitió una mejor formación académica artística y pedagógica, así como una mejor calificación profesional.

El Plan de Estudios tuvo un total de 30 créditos, 24 créditos (80\%), corresponden al área artística y 6 créditos al área pedagógica (20\%).

Para concluir este apartado, deseo dejar constancia de la responsabilidad que las Escuelas de Artes Plásticas y de Formación Docente asumen con la educación costarricense, capacitando y ofreciendo cursos de la mejor calidad a educadores para que participen en la formación integral de nuestros jóvenes.

\section{Planes de estudio en el área de la enseñanza de las Artes Plásticas}

La Facultad de Educación de la Universidad de Costa Rica, tiene sus orígenes en las "secciones" normales" abiertas por don Mauro Fernández, en el Liceo de Costa Rica en 1887, y en el Colegio Superior de Señoritas en 1888. Estas secciones son la base de la Escuela Normal de Costa Rica, creada en 1914. Pero es en 1915 cuando inicia sus funciones como institución exclusiva y dedicada a la formación de maestros.

La Escuela Normal de Costa Rica se convierte en la Escuela de Pedagogía al incorporarse en 1940 a la Universidad de Costa Rica, con sede en San José. Este hecho le otorga al docente la categoría de profesional universitario. En 1957, la Escuela de Pedagogía se transforma en la Facultad de Educación. Los planes de estudio de esta Facultad, aprobados a fines de 1970, consolidan en forma definitiva las aspiraciones que durante más de medio siglo propician en Costa Rica, destacados educadores como Arturo Torres, Roberto Brenes Mesén, Joaquín García Monge, y Omar Dengo. Cortés, R. (1972).

Desde 1940, la Universidad de Costa Rica, por medio de las Facultades de Ciencias y Letras, y la de Bellas Artes, ofrecen en forma conjunta planes de estudio para la formación de profesores, con énfasis en la enseñanza de las Artes Plásticas.

Los planes de formación para profesores de segunda enseñanza tienen una duración de cuatro años y comprenden asignaturas en tres áreas diferentes: Cultura General impartida por la Escuela de Estudios Generales; la de Cultura Académica Especializada ofrecida por la Escuela de Artes Plásticas, y la Formación Pedagógica a cargo de la Escuela de Formación Docente.

En 1974 el Consejo Universitario, se pronunció a favor de los planes de estudio conducentes al grado de Bachiller en Enseñanza de cada una de las áreas académicas, a la 
vez se eliminó el título de profesor de segunda enseñanza. Al respecto, el Estatuto Orgánico en su artículo 205 expresa:

La Universidad confiere los siguientes grados académicos: Bachillerato Universitario, Licenciatura, Maestría y Doctorado; éstos últimos como culminación de estudios graduados", la comunicación oficial surge de la "Sesión número 40", celebrada el día 14 de Octubre de 1974, en el Consejo Asesor de la Facultad de Educación y aprueba el cuadro estructural orientado al Plan de Bachillerato en la Enseñanza de cada una de las áreas de enseñanza", entre las que se encontraba la correspondiente a las Artes Plásticas. Cabe destacar que en la actualidad, se continúan ofreciendo los Bachilleratos en la Enseñanza Secundaria, pero con una salida lateral llamada Profesorado, la cual se ofrece concluido el tercer año de estudios.

\subsection{El Bachillerato en la Enseñanza de las Artes Plásticas (plan vigente)}

\begin{tabular}{|c|c|c|}
\hline \multicolumn{3}{|c|}{ Bachillerato en la Enseñanza de las Artes Pláticas } \\
\hline Área de formación & Créditos & $\%$ \\
\hline Cultura General Humanística & 18 & $12,7 \%$ \\
\hline Especialización Académica Artística & 78 & $54,9 \%$ \\
\hline Formación Pedagógica & 46 & $32,4 \%$ \\
\hline Totales & 142 & $100 \%$ \\
\hline
\end{tabular}

Como parte de la información recopilada, es importante mencionar que la Universidad de Costa Rica enfrenta los retos que la sociedad demanda ofreciendo planteamientos curriculares novedosos, que permiten el replanteamiento de programas de estudio que la población estudiantil y la sociedad requieren. Con este propósito, realizaré un comentario del Plan de Estudios vigente.

Es importante indicar que la estructura curricular de este plan de estudios, está conformado por tres áreas consideradas fundamentales en la formación de los docentes de Artes Plásticas: área de Cultura General Humanística, área de Especialización Académica Artística y área de Formación Pedagógica.

Como parte de los requisitos para hacer el ingreso al Bachillerato en la Enseñanza de la Artes Plásticas en la Universidad de Costa Rica, los estudiantes deben aprobar el examen 
de admisión o prueba de aptitud académica, así como la prueba de habilidad establecida por la Escuela de Artes Plásticas, lo que le permite a esta Unidad Académica seleccionar a sus estudiantes, desde un planteamiento más objetivo.

\section{- Área de cultura general humanística}

La visión humanista que posee el plan de estudios es fundamental, ya que responde al planteamiento filosófico de la Universidad de Costa Rica, desde su nacimiento, el cual consiste en inspirar y desarrollar el interés permanente por la cultura general y humanística, así como crear una conciencia crítica por la problemática costarricense, latinoamericana y mundial. (Estatuto Orgánico de la Universidad de Costa Rica 2000).

Acorde con esta visión de humanismo, esta área esta conformada por los siguientes cursos: Humanidades, actividad deportiva y artística, repertorios, Seminarios de Realidad Nacional I y II, así como el Trabajo Comunal Universitario de 300 horas de trabajo debidamente planificado y sistematizado que el estudiante debe brindar al país sin remuneración alguna.

La formación humanista según Rodrigo Facio, esta inspirada por un ideal pedagógico que no es tanto enseñar, como enseñar a aprender, no es tanto decir lo que hay que pensar, como inducir a pensar. Formar un técnico sobre el hombre de ciencia y el hombre de ciencia sobre el hombre culto, moral y socialmente responsable. Con esta fundamentación filosófica, la Escuela de Estudios Generales de la Universidad de Costa Rica, coadyuva en la formación humanista del futuro educador permitiéndole participar en la educación costarricense, desde una perspectiva holística.

\section{- Área de especialización académica-artística}

Corresponde a la formación artística impartida por la Escuela de Artes Plásticas. De acuerdo con el planteamiento curricular que ofrece esta Escuela, el Plan de estudios ofrece a los estudiantes una formación general con cursos considerados básicos para su futura formación, entre los cursos se citan los siguientes: Dibujo, Diseño, Introducción a la Pintura, Introducción a la Escultura, Historia del Arte, Filosofía del Arte, Cerámica, Serigrafía, Xilografía, Grabado en Metal, Textiles, así como la aprobación de cursos optativos que le permiten al futuro docente, complementar su formación artística. Además de los cursos mencionados, cabe mencionar que los estudiantes deben aprobar otros denominados "énfasis", que le permiten profundizar su área de formación artística en los siguientes énfasis que ofrece la Escuela: pintura, escultura, cerámica, grabado y artes gráficas. 
Como se indica anteriormente, los cursos que corresponden a esta área expresiva le permiten al futuro docente, una formación artística de calidad, lo que los faculta al logro de experiencias de arte enriquecedoras, mediante las cuales los estudiantes pueden cumplir con los objetivos que propone el Ministerio de Educación Pública.

\section{- Área de formación pedagógica}

Corresponde al conjunto de cursos que imparten la Escuelas de Formación Docente en coordinación con las de Administración Educativa y la Escuela de Orientación y Educación Especial.

Esta área comprende dos sub-áreas: los fundamentos educativos y la didáctica.

- La sub-área conformada por los Fundamentos Educativos, estudia las corrientes filosóficas, sociológicas y psicológicas de la educación general, aunque se enfatiza en la educación costarricense.

- La sub-área correspondiente a la didáctica incluye el estudio de conocimientos y destrezas necesarias para desarrollar los procesos de enseñanza y aprendizaje. Los cursos correspondientes tienen como referencia inmediata y campo de aplicación, el trabajo docente de las aulas del tercer ciclo de educación diversificada. Esa sub-área se completa con el estudio de aspectos básicos de la investigación educativa, específicamente en la elaboración de breves investigaciones que los diversos cursos exigen, con el fin de estimular la observación y el análisis de trabajo en el aula. Plan de Profesorado y Bachillerato en la Enseñanza, (1991).

Se considera importante indicar que esta área de formación le permite al estudiante experiencias directas en las aulas del sistema educativo, ya que como parte de su formación académica, debe llevar a la práctica y en situaciones formales de aula, todos los conocimientos adquiridos durante su formación.

El propósito de esta área es estimular la actitud hacia la docencia, así como desarrollar los conocimientos, habilidades y las destrezas necesarias para que el futuro docente sea capaz de permitirle al joven estudiante, un desarrollo armónico de su personalidad, en donde las actividades que organiza dentro del contexto de aula estén encaminadas a facilitar procesos de construcción y de apropiación del conocimiento, así como al desarrollo de las habilidades y destrezas propias del programa de Artes Plástica emanado por el Ministerio de Educación Pública. 


\section{Mercado de trabajo}

De acuerdo con la formación recibida en las Escuelas de: Estudios Generales, Formación Docente y Artes Plásticas, la Universidad de Costa Rica otorga el "Bachillerato en la Enseñanza de las Artes Plásticas". Este título le permite al docente desempeñarse de manera prioritaria como profesor de Artes Plásticas en instituciones de educación secundaria, tanto públicas como privadas, aunque también puede impartir lecciones en instituciones de enseñanza primaria.

A continuación, se hace un resumen con las diversas opciones de trabajo que donde se pueden desempeñar de manera óptima:

- Profesores en instituciones de educación secundaria.

- Maestros de Artes Plásticas en instituciones de educación primaria.

- Instructores en academias de arte

- Profesores de escultura, pintura, grabado y cerámica en instituciones de nivel superior; dado que estos estudiantes pueden continuar estudiando en la Escuela de Artes Plásticas para obtener el título de Licenciatura en cualquiera de los siguientes énfasis: cerámica, escultura, pintura, grabado y artes gráficas.

- Como artistas profesionales pueden generar sus propios talleres de arte.

Como puede verse, los estudiantes del Bachillerato en la Enseñanza de las Artes Plásticas, una vez egresados de la Universidad, tienen diversas opciones de trabajo, dado que la formación ofrecida en las áreas artística, pedagógica y humanística, les permite desempeñarse de manera óptima en cualquiera de los campos laborales mencionados.

\section{Conclusiones}

La literatura indagada evidencia que, a pesar de los escasos recursos económicos con que ha contado nuestro país desde sus orígenes, nuestros presidentes han impulsado de manera decisiva la educación.

De la misma manera, la Universidad de Costa Rica, a través de las Escuelas de Estudios Generales, Artes Plásticas y Formación Docente, no ha escatimado esfuerzos para ofrecer una eficiente formación humanística, artística y pedagógica a los profesores de Artes Plásticas. Por consiguiente, quienes desean estudiar enseñanza de las Artes Plásticas en 
esta Universidad, logran un nivel académico elevado, que les permite ejercer exitosamente sus funciones docentes en el aula, mediante prácticas artísticas y pedagógicas innovadoras para el logro de los objetivos generales de las Artes Pláticas que propone el Ministerio de Educación Pública, a saber :

- Proporcionar actividades de taller (teórico-práctico) con temas incentivadotes, utilizando los elementos del leguaje plástico y los elementos estéticos.

- Impulsar experiencias artístico-plásticas que contribuyan al desarrollo sensorial, motriz y afectivo (goce estético, apreciación, conocimiento teórico y producción artística).

- Promover el arte y los aportes artísticos nacionales y extranjeros en el tiempo y el espacio para el enriquecimiento cultural y el estímulo a la creatividad.

- Promover la valoración de las artes plásticas, desde una visión humanista y científica

- Promover actividades artísticas que favorezcan la realidad ecológica del medio y su relación con el mundo.

- Promover la participación de actividades artísticas en al cuales se manifiesten los valores estéticos, morales, éticos e intelectuales de la sociedad costarricense como parte de un país democrático.

- Preservar las costumbres, las tradiciones, el folklore y los valores culturales, mediante la realización de experiencias estéticas

(Ministerio de Educación Pública. 2001).

En los objetivos mencionados, se contempla una importante relación y equilibrio entre los dominios cognoscitivo, afectivo y psicomotor, que vienen a ser las directrices o puntos de partida del profesor, por lo que es necesaria la formación de excelentes profesionales, poseedores de una vasta cultura, de un gran conocimiento y experiencia en el campo de la educación artística, pedagógica y humanista, que les permita la creación de actividades artísticas y didácticas con base en los objetivos citados.

\section{Referencias}

Cortés, R. (1985). La Facultad de Educación en la Educación Pública Costarricense. Documento inédito, Facultad de Educación.

Escuela de Formación Docente, (1985). Fascículo 3202. Facultad de Educación. Catálogo General. Universidad de Costa Rica.

Escuela Normal Superior. (1969). Programas para el II curso de verano. San José, C.R.: La Escuela. 
Gutiérrez, J. (1969). Seminario Nacional de Problemas en la Educación. San José, C.R.: [s.I.]

León, E. (1982). Una universidad en una ciudad de maestros. Heredia, Costa Rica: EUNA.

Lowenfeld, V. y Lambert, B. (1984). Desarrollo de la Capacidad Creadora. Buenos Aires: Editorial Kapelusz.

Ministerio de Educación Pública. Escuela Normal Superior, Departamento de Artes Plásticas. (1969). Programas para el Curso de Verano. San José, C.R.: El Ministerio.

Panero de, Norma y otros. (2001). EDUCACIÓN ARTísTICA Y C.B.C. Talleres de Plástica, Música, Teatro y Expresión Corporal. $2^{\mathrm{a}}$ ed. Serie Educación. Santa Fe, Argentina: Homo Sapiens Ediciones.

República de Costa Rica. (1902). Boletín de la Escuelas Primarias. Revista Quincenal. Tomo 14, Número 92. San José.

Universidad de Costa Rica. (1949). Reglamento General de la Escuela de Bellas Artes. San José, C.R.: Editorial de la Universidad de Costa Rica.

Universidad de Costa Rica, Decanato de la Facultad de Educación. (2001). Planes de Estudio. San José, C.R.: Editorial de la Universidad de Costa Rica.

Villegas W. (1970). Artes Plásticas I. Escuela Normal Superior-División de Capacitación. Cursos de verano. San José, C.R.: MEP. 
